\title{
Living Among the Dead in the Manila North Cemetery: A Cartographic Re-Imagination
}

\author{
Algura, Patricia O.
}

University of the Philippines Diliman, poalgura@up.edu.ph

Keywords: Art, Cartography, Contemporary Map, Map Art

\begin{abstract}
:
Cemeteries are often regarded as left behind landscapes: scary and lifeless, abandoned and forgotten. Despite this derelict image, residents of Manila North Cemetery are living and co-existing in tombs and mausoleums. They celebrate life and live behind the shadows of those who have passed on. The maps present the unseen life in the spaces of the cemetery. Behind the dark and shadows of the departed are faces of people with bright smiles and with inspiring dreams. Through ethnographic research, interviews and observations were conducted to uncover and recover stories of life and experiences that were used as the basis, foundation, and inspiration of the maps. Using the actual map of the cemetery, a series of maps were realized to portray stained-glass images of mother and child, Mother Mary, and angel, where colors represent the vibrant life and the promise of afterlife in the cemetery.

These maps tell a whole different story, giving light to the life rather than the dead. The Mother and child map shows how adults in the cemetery are doting parents and siblings. Elders were responsible for providing the needs and nourishing the family. As part of the Philippine culture, Filipinos are family-oriented, and they tend to remain close to their families even if the child is grown up - gainfully employed or has married. The portrait of Mother Mary symbolizes Filipinos' Christian faith. The smiles on faces are evidences of hope and faith. Living in what society considers an undesirable disposition, the people are determined and always hopeful for tomorrow. The departed are depicted as the angel, as it shows how the living and the dead are at peace and coexisting in the same environment. We, as outsiders, often hear about ghosts, horror stories, and consider cemeteries as haunted, but these events and stories are uncommon to the residents. They had established a relationship with the place and those around it. For them, the cemetery is not merely a place, but a place they call home.
\end{abstract}

The maps demonstrate that the living and the dead can co-exist in the same space rather than separated. These cartographic works are interventions to depict, portray, and represent urban life that exist in the peripheries of the city of Manila. 


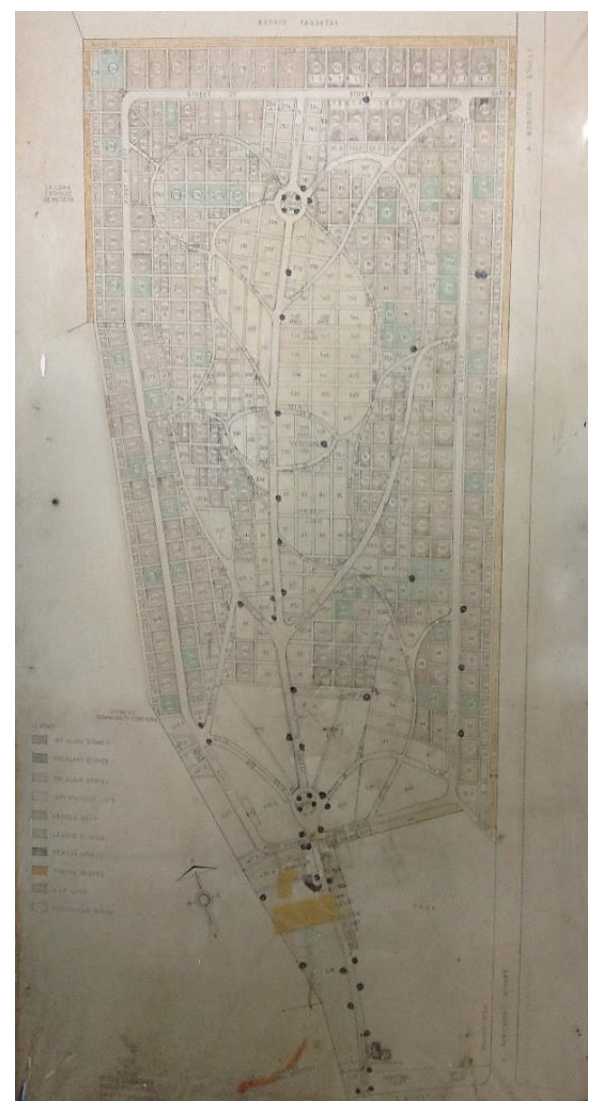

Figure 1. Actual map of Manila North Cemetery
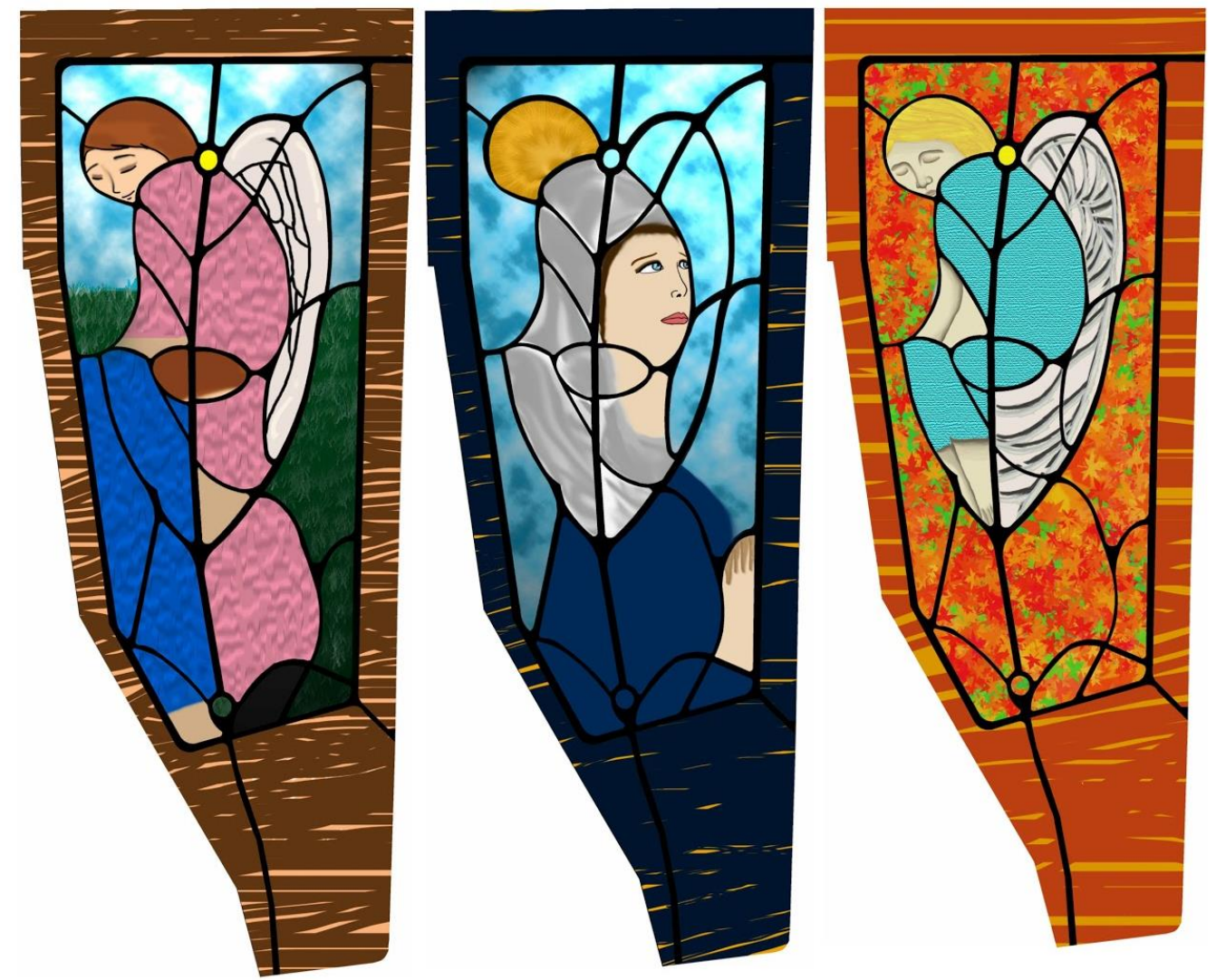

Figure 2. Manila North Cemetery Map Arts (From the left: Mother and Child, Mother Mary, Angel 